\title{
Etiologia e epidemiologia das dermatofitoses em Goiânia, GO, Brasil
}

\author{
Etiology and epidemiology in dermatophytosis in Goiânia, State of Goiás, Brazil \\ Théo Rodrigues Costa, Márcio Rodrigues Costa, Marcelo Vieira da Silva, Adriana \\ Batista Rodrigues, O rionalda de Fátima Lisboa Fernandes, Ailton José Soares e \\ Maria do Rosário Rodrigues Silva
}

\begin{abstract}
Resumo As dermatofitoses são infecções superficiais capazes de produzir lesões em tecidos queratinizados, como pele, pêlo e unhas. Foram examinados 6068 indivíduos procedentes de Goiânia, com suspeita clínica de infecções fúngicas, durante 5 anos (1993-1997), verificandose a incidência e a etiologia das dermatofitoses nos referidos pacientes. Material coletado de várias regiões corpóreas permitiu caracterizar 1595 dermatófitos em 1345 indivíduos. A identificação dos dermatófitos realizada através de cultivo em ágar Sabouraud e microcultivo em lâmina, permitiu verificar uma maior freqüência de Trichophyton rubrum (37,4\%), T. mentagrophytes $(36,4 \%)$ e Microsporum canis (16\%). Os dermatófitos foram mais freqüentemente encontrados produzindo lesões nos pés (30,5\%), região inguino crural $(17,8 \%)$ e região glabra do corpo (15,5\%). Foi analisada a distribuição corporal das lesões de dermatofitoses com os respectivos agentes etiológicos encontrados. Melhores condições higiênicas e diagnóstico precoce da doença são necessários para controlar e diminuir a incidência de dermatofitoses na nossa região.
\end{abstract}

Palavras-chaves: Dermatofitoses. Trichophyton rubrum. Trichophyton mentagrophytes. Microsporum canis.

\begin{abstract}
Dermatophytoses are superficial infections that may lead to lesions of keratinized tissues, like skin, hair and nails. A total of 6068 individuals from Goiânia, GO, with suspected dermatophytic lesions were examined over a period of five years (1993-1997) in order to determine the incidence and etiology of dermatophytosis. Material collected from different body parts was submitted to direct microscopic examination using $\mathrm{KOH}$, cultured in Sabouraud agar and microscopically examined for colony morphology, with the identification of 1595 dermatophytes. Trichophyton rubrum (37.4\%), T. mentagrophytes (36.4\%) and Microsporum canis (16\%) were the species most frequently isolated. Dermatophytes were more frequently found producing lesions in the feet (30.5\%), inguinal and crural regions $(17,8 \%)$ and glabrous body regions (15.5\%). The distribution of the different infected body sites was determined in terms of the respective etiologic agents found. Better hygiene conditions and an early diagnosis are the most important tools to control and reduce the incidence of dermatophytosis in Goiânia, GO.
\end{abstract}

Key-words: Dermatophytosis. Trichophyton rubrum. Trichophyton mentagrophytes. Microsporum canis.

Departamento de Microbiologia, Imunologia e Parasitologia do Instituto de Patologia Tropical e Saúde Pública da Universidade Federl de Goiás, Goiânia, GO.

Endereço para correspondência: Profa Maria do Rosário R. Silva. Av. Delenda de Rezende, s/nº, Setor Universitário, Caixa Postal 131, 74605-050 Goiânia, GO, Brasil.

Recebido para publicação em 1/6/98. 
As dermatofitoses são infecções cutâneas causadas por fungos queratinofílicos denominados dermatófitos, que compreendem os gêneros Microsporum, Epidermophyton e Trichophyton, semelhantes em sua morfofisiologia, imunologia e taxonomia 19 11. As dermatofitoses apresentamse como as infecções fúngicas mais comuns em países tropicais, constituindo um problema de saúde pública e refletindo baixo nível de educação sanitária9. A distribuição e freqüência das dermatofitoses e seus agentes etiológicos variam segundo a região geográfica e o nível sócio econômico da população1 10.

A freqüência das dermatofitoses e sua etiologia têm sido relatada em Goiás por Machado et al8 e Fernandes et al3, verificando-se diferenças na etiologia das dermatofitoses. O presente trabalho tem como objetivo contribuir para o conhecimento da freqüência e etiologia das dermatofitoses em Goiânia-GO, durante o período de 1993-1997.

\section{MATERIAL E MÉTODOS}

Pacientes. Os 6068 pacientes examinados no estudo foram procedentes do Ambulatório de Dermatologia do Hospital das Clínicas da UFG e de clínicas particulares de Goiânia enviados ao laboratório de Micologia do Instituto de Patologia Tropical e Saúde Pública para diagnóstico micológico no período de 19931997. De todos os indivíduos foram registrados dados referentes ao sexo, idade e local da lesão.

Coleta, isolamento e identificação. Amostras de pele, pêlo e unhas de pacientes com dermatofitoses, foram colhidas, usando-se a raspagem de descamações de pele e de unhas, enquanto no couro cabeludo, além das descamações, retirava-se o pêlo danificado com pinça esterilizada. $\mathrm{O}$ exame micológico desses materiais consistiu na realização do exame microscópico usando-se $\mathrm{KOH}$ a $40 \%$ para clarificação do material e no cultivo em meios de ágar Sabouraud dextrose, ágar específico para fungos patogênicos e ágar batata-dextrose mantidos à temperatura ambiente por no mínimo 30 dias.

A identificação dos dermatófitos foi feita observando-se as características macroscópicas como cor, superfície e reverso da colônia, e características microscópicas como a forma, tamanho e disposição dos conídios. Incluiu-se ainda o microcultivo em lâmina (usando-se ágar batata para estimular a formação dos elementos de frutificação, permitindo uma melhor caracterização dos isolados); teste da perfuração do pêlo in vitro e testes bioquímicos como o teste da urease, estes últimos, usados na diferenciação entre $T$. rubrum e T. mentagrophytes.

\section{RESULTADOS}

Dos 6068 indivíduos suspeitos de infecções fúngicas isolou-se $1595(26,3 \%)$ cepas de dermatófitos. Estes isolados pertenciam a 1345 pacientes examinados, sendo 680 pertencentes ao sexo masculino e 665 ao feminino.

A tinha dos pés foi a dermatofitose mais encontrada, com $488(30,6 \%)$ casos, sendo mais comum entre 31 e $40(25,4 \%)$ anos, enquanto tinha do couro cabeludo foi observada em 208 $(13,04 \%)$ casos, sendo que destes, 185 (88,9\%) foram de crianças menores de 10 anos. Unha da mão e mão também foram locais de lesões por dermatófitos com $59(3,7 \%)$ e 121 (7,6\%) casos respectivamente, observados predominantemente na fase adulta. A distribuição das lesões correlacionado à idade dos pacientes encontrase na Tabela 1, enquanto a porcentagem de lesões por dermatófitos de acordo com as regiões do corpo envolvidas encontram-se na Figura 1.

Os dermatófitos isolados em ordem de freqüência foram: T. rubrum, observado em 597
$(37,4 \%)$ lesões, T. mentagrophytes em 581 (36,4\%), M. canis em $256(16,0 \%)$, T. tonsurans em 94 (5,9\%), E. floccosum em 58 (3,6\%) e M. gypseum em $9(0,6 \%)$. Todos os agentes etiológicos de dermatofitoses identificados encontram-se na Figura 2.

Com relação a etiologia das lesões nas diferentes regiões do corpo verificou-se que $M$. canis é o agente que mais acomete o couro cabeludo com $70,7 \%$ (147/208) dos isolados seguido de T. tonsurans com 18,3\% (38/208). Nos pés, verificou-se predominância de T. mentagrophytes e T. rubrum, com $44,9 \%$ $(219 / 488)$ e $43,9 \%(214 / 488)$ dos casos, respectivamente (Tabela 2 ).

Correlacionando-se o agente etiológico com a faixa etária do paciente, verificou-se que entre 0 a 10 anos $M$. canis figura como o principal agente e entre os 21 a 30 anos destaca-se T. mentagrophytes com 159 casos (Tabela 3). 
Tabela 1 - Distribuição das lesões de dermatofitose segundo idade do paciente.

\begin{tabular}{|c|c|c|c|c|c|c|c|}
\hline \multirow[b]{2}{*}{ Local } & \multicolumn{7}{|c|}{ Idade } \\
\hline & $0-10$ & $11-20$ & $21-30$ & $31-40$ & $41-50$ & $>50$ & Total \\
\hline Mão & 4 & 15 & 24 & 29 & 24 & 25 & 121 \\
\hline Pé & 3 & 56 & 109 & 124 & 92 & 104 & 488 \\
\hline Corpo & 31 & 43 & 58 & 46 & 34 & 36 & 248 \\
\hline Unha da mão & 0 & 7 & 10 & 13 & 8 & 21 & 59 \\
\hline Unha do pé & 0 & 10 & 39 & 38 & 40 & 62 & 189 \\
\hline Couro cabeludo & 185 & 14 & 3 & 4 & 0 & 2 & 208 \\
\hline Região crural & 9 & 48 & 92 & 53 & 54 & 26 & 282 \\
\hline Total & 232 & 193 & 335 & 307 & 252 & 276 & 1595 \\
\hline
\end{tabular}

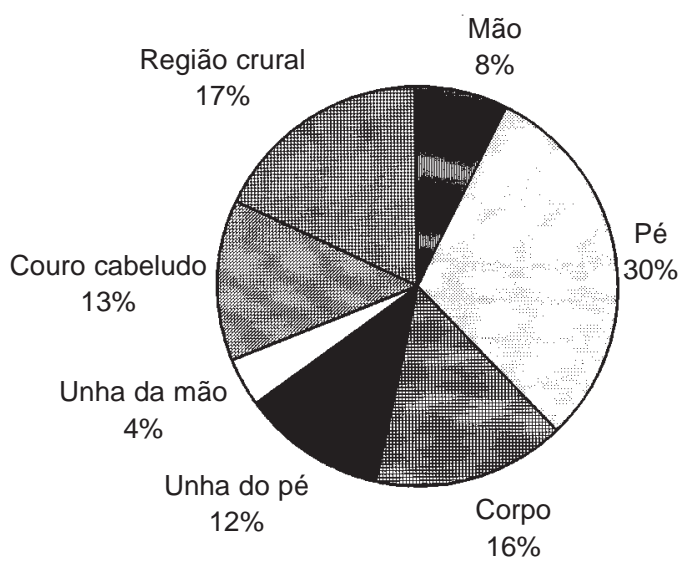

Figura 1 - Distribuição das dermatofitoses de acordo com a localização das lesões.

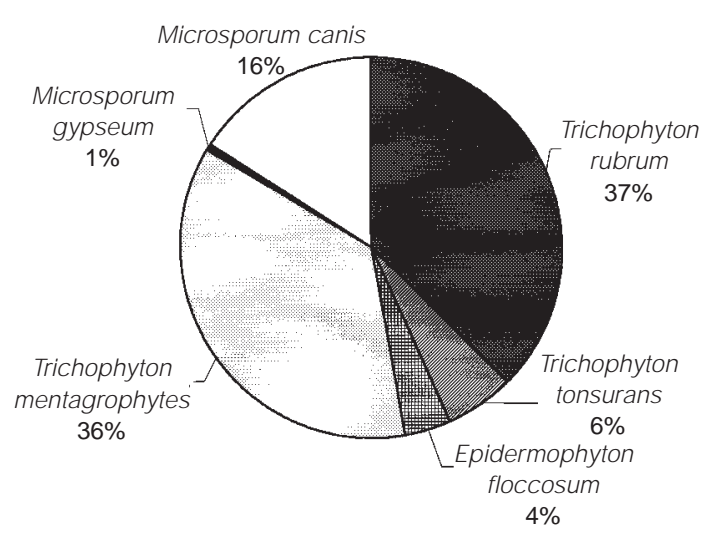

Figura 2 - Frequência das espécies de dermatófitos observada em 1595 casos de dermatofitoses.

Tabela 2 - Distribuição das espécies de dermatófitos segundo localização das lesões.

\begin{tabular}{|c|c|c|c|c|c|c|c|}
\hline \multirow[b]{2}{*}{ Local } & \multicolumn{7}{|c|}{ Agente } \\
\hline & T. tonsurans & T. mentagrophytes & T. rubrum & M. canis & M. gypseum & E. floccosum & Total \\
\hline Mão & 6 & 59 & 49 & 2 & 0 & 5 & 121 \\
\hline Pé & 17 & 219 & 214 & 20 & 0 & 18 & 488 \\
\hline Corpo & 6 & 90 & 95 & 47 & 5 & 5 & 248 \\
\hline Unha da mão & 9 & 16 & 23 & 11 & 0 & 0 & 59 \\
\hline Unha do pé & 12 & 77 & 95 & 3 & 0 & 2 & 189 \\
\hline Couro cabeludo & 38 & 14 & 5 & 147 & 3 & 1 & 208 \\
\hline Região crural & 6 & 106 & 116 & 26 & 1 & 27 & 282 \\
\hline Total & 94 & 581 & 597 & 256 & 9 & 58 & 1595 \\
\hline
\end{tabular}

$\mathrm{T}=$ Trichophyton; $\mathrm{M}=$ Microsporum $; \mathrm{E}=$ Epidermophyton. 
Tabela 3 - Distribuição das espécies de dermatófitos segundo a idade do paciente.

\begin{tabular}{lrrrrrrr}
\hline & \multicolumn{7}{c}{ Idade } \\
\cline { 2 - 8 } Agente & $0-10$ & $11-20$ & $21-30$ & $31-40$ & $41-50$ & \multicolumn{1}{c}{ Total } \\
\hline T. tonsurans & 49 & 18 & 6 & 5 & 6 & 10 & 94 \\
T. mentagrophytes & 24 & 51 & 159 & 115 & 56 & 70 & 475 \\
T. rubrum & 12 & 64 & 92 & 113 & 114 & 101 & 496 \\
M. canis & 164 & 13 & 13 & 9 & 7 & 10 & 216 \\
M. gypseum & 6 & 0 & 0 & 0 & 0 & 2 & 8 \\
E. floccosum & 3 & 9 & 9 & 10 & 12 & 13 & 56 \\
\hline Total & 258 & 155 & 279 & 252 & 195 & 206 & 1345
\end{tabular}

$\mathrm{T}=$ Trichophyton; $\mathrm{M}=$ Microsporum; $\mathrm{E}=$ Epidermophyton.

\section{DISCUSSÃO}

O isolamento de 1595 (26,3\%) dermatófitos obtidos de 6068 pacientes com suspeita clínica de infecção fúngica mostra que a dermatofitose é a mais comum entre as infecções dermatológicas. Em Vitória, ES, Mattêde et al10 detectaram um percentual de $50,21 \%$ de dermatofitoses em 470 pacientes atendidos no Hospital Universitário de Vitória. Em Navarra, na Espanha, Mazon et al11 verificaram uma incidência de 20,8\% de dermatofitoses em 1375 pacientes suspeitos de infecção fúngica, durante 5 anos.

As dermatofitoses ocorrem preferencialmente em adultos jovens, em localizações como unhas, pés e pele lisa do corpo, enquanto as lesões do couro cabeludo são mais comumente diagnosticadas em crianças 5 11. Na casuística estudada, verificou-se a ocorrência de 642 lesões presentes em indivíduos na faixa etária de 21 a 40 anos, localizadas preferencialmente nos pés, região lisa do corpo e região inguino crural, enquanto as lesões do couro cabeludo causadas principalmente por $M$. canis, predominavam entre as crianças de 0-10 anos. Mazon et al11 acreditam que o elevado número de tinha dos pés ocorra devido ao aumento de práticas desportivas e à proliferação do uso de calçados fechados. A presença de lesões no couro cabeludo em crianças, têm sido explicada por Hay6 pela ausência de ácido graxos de cadeia de longitude média (C8-C12), os quais são capazes de inibir o crescimento de dermatófitos nessa região, enquanto Londero et al7 acreditam que esta maior incidência em crianças deve-se provavelmente ao maior contágio com a fonte habitual, que são os animais domésticos, principalmente o gato.
T. mentagrophytes foi o principal causador desta infecção nos pés dos indivíduos estudados. Este agente antropofílico é considerado causa comum de tinha dos pés, ocorrendo principalmente em climas temperados e subtropicais 26 . E. floccosum foi observado na região crural em $27(46,6 \%)$ de 58 isolados. Este fungo, também antropofílico é normalmente detectado em regiões encobertas do corpo como região inguinal e glútea10. De todos os dermatófitos zoofílicos, $M$. canis é o de maior prevalência em todo mundo, associado geralmente às lesões do couro cabeludo, sendo que de 208 lesões observadas em nossa casuística no couro cabeludo, 147 possuíam esta espécie como agente etiológico .

O predomínio de T. rubrum encontrado já havia sido também observado na nossa região por Machado et al8, durante o período de 19671973, enquanto Fernandes et al3 durante estudo realizado de 1984 a 1990, encontraram predominantemente $T$. mentagrophytes. Comparando-se os nossos achados com o trabalho de Fernandes et $\mathrm{al}^{3}$, verificamos um aumento da espécie $M$. canis, detectado em 16\% dos casos contra $11,4 \%$ verificado por estes pesquisadores, e uma diminuição da espécie T. tonsurans, detectada em $5,9 \%$ dos nossos casos contra $16 \%$. A distribuição irregular na etiologia das dermatofitoses em diferentes regiões geográficas ou até em uma mesma região, de uma época para outra, tem sido explicada por alterações nas condições de vida dos indivíduos, pelas constantes migrações humanas, pela influência de animais domésticos e pela idade da população 4 .

\section{REFERÊNCIAS BIBLIOGRÁFICAS}

1. Boncompte E, Algueró M, Videla S, Forn J. Contribuition al estudio de las dermatomicosis en Cataluña. Revista Iberoamericana Micología 14:26-28, 1997.
2. Campbell IT, Campbell GAM, Santos MG, Sant'ana AVD, Sousa MV, Costa IM. Incidência dos Dermatófitos em Brasília. Anais Brasileiros Dermatologia 53:257-261, 1978. 
3. Fernandes OFL, Silva MRR, Vilela NA, Silva ER, Silva HM, Jesuino RS. Etiologia das dermatofitoses em pacientes atendidos no laboratório de Micologia do IPTSP da UFG. Revista Patologia Tropical, 21:189-197, 1992.

4. Gianelli MA, Araújo MAR, Proença NG, Zaitz C. Dermatofitose do pé: estudo epidemiológico prospectivo. Anais Brasileiros Dermatologia 63:9-12, 1988.

5. Gil RE, Vera MJR, Muñoz MK. Estudio etiológico y epidemiológico de las dermatomicosis en Madrid. Revista Clínica Espanhola, 178:377-379, 1986.

6. Hay RJ. Dermatoficias y otras micosis superficiais. In: Mandell GL, Gordon Douglas R, Bennett JE (eds) Enfermedades Infecciosas. Principios y práctica. Buenos Aires, Panamericana, 2137-2149, 1991.

7. Londero AT, Ramos C, Lauda P. Os dermatófitos no interior do Rio Grande do Sul. O Hospital 61:161-165, 1962.
8. Machado OP, Rodrigues MR, Souza MHR. Ocorrência de dermatófitos em Goiás. Revista Patologia Tropical 3:273-276, 1977.

9. Martini JP, Souza LC, Costa HC. Dermatófitos isolados em pacientes do Hospital "Lauro de Souza Lima" Salusvita 6:1-6, 1987.

10. Mattêde MGS, Coelho CC, Mattêde AF, Perin FC, Palhano Júnior L. Etiologia das dermatofitoses em Vitória (ES). Anais Brasileiros Dermatologia 61:177-182, 1986.

11. Mazón A, Salvo S, Vives R, Valcayo A, Sabalza MA. Estudio etiológico y epidemiológico de las dermatofitosis en Navarra (España). Revista Iberoamericana Micologia 14:65-68, 1997. 